Obituary

\title{
Chris Silagy
}

C ris Silagy, professor of public health and foundation director of Services Research, died on 13 December 2001. He was 41 and had been in his current post since 1999, taking on this new challenge two years after being diagnosed with non-Hodgkin's lymphoma. The news of his death was relayed rapidly around the world. Within 24 hours his self-written obituary appeared on the $B M J$ website. In death, as in life, Chris's particular gift was his ability to infuse his high profile public achievements with open and direct communication at a personal level. The many tributes posted on the $B M J$ website in the following week showed the affection and respect that this combination evoked.

He achieved a great deal in a short time, both in his native Australia and across the world. After completing his $\mathrm{PhD}$ at Monash, he spent 1991-93 as the Sir Robert Menzies scholar at Oxford, where he became closely associated with the work of the then fledgling Cochrane Collaboration. He applied himself to all the developmental work in progress at the time. He built a register of trials in smoking cessation, single handedly searched primary care journals for trial reports, field tested the evolving software, and conducted high quality systematic reviews. His review of nicotine replacement therapy became a model used to train others.

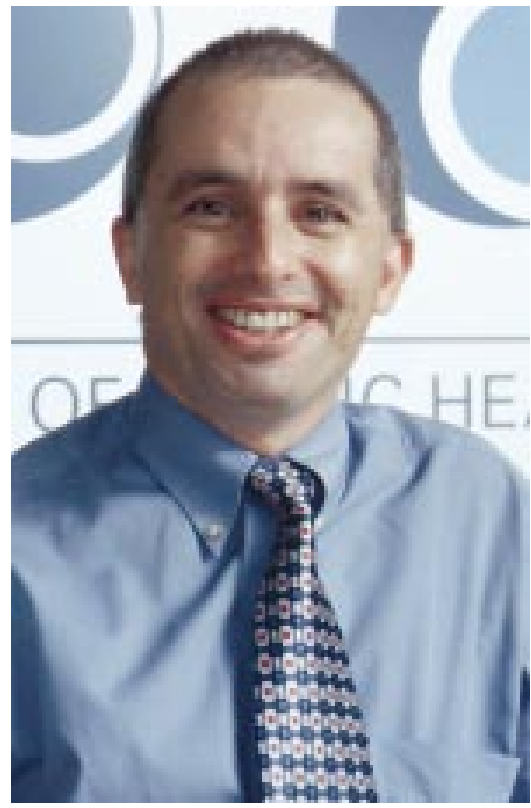

Returning to Australia as professor of general practice at Flinders, he played an important part in developing primary care research and teaching in Australia, while continuing to help build the Cochrane Collaboration. In 1994, he established the Australasian Cochrane Centre, and from 1996-98 he took on a key international role as chair of the
Cochrane Collaboration at a time of rapid expansion.

Although tobacco control was just one of a broad range of interests, Chris's contributions to this field were substantial. In 1995, he set up the Cochrane Tobacco Addiction Review Group with the aim of providing up to date and reliable summaries of the evidence for those involved in tobacco policy, research, and clinical care. He was content, the group established, to leave hands-on editing to others. But he continued to play an important strategic role, continually challenging the group to reconsider and develop its editorial processes. During a sabbatical in autumn 2000 he investigated the impact of the group's work on development of guidelines for smoking cessation, publishing the results just months before he died. He was also conscientious as a reviewer, completing the sixth substantive update of the nicotine replacement therapy review during his sabbatical.

As a champion of the evidence based approach in health care, Chris was inevitably a focus for critics of the movement. Through his energy and charm, he ensured that the issues were always debated with intelligence and good humour.

Chris leaves his wife, Jane, a general practitioner, and four sons.

Tim Lancaster tim.lancaster@public-health.oxford.ac.uk

\section{3rd European Conference on Tobacco or Health "Closing the Gaps - Solidarity for Health"}

The 3rd European Conference on Tobacco or Health will take place in Warsaw, Poland from 20 to 22 June 2002.

The goal of the $3 \mathrm{ECTOH}$ is to mobilise Europeans to improve health through tobacco control. What we need, besides broad implementation of comprehensive tobacco control policies and smoking cessation programs throughout Europe, is European solidarity for health. Our conference will consolidate and strengthen European action towards health improvement by reducing the exposure to tobacco in all its forms

The conference is dedicated to all people engaged in tobacco control and smoking cessation activities, including health care professionals, public health leaders, tobacco control advocates and smoking cessation practitioners, mass media representatives, economists and politicians. However, the fight against chronic tobacco-related diseases in Europe, including cancer, heart and lung disease cannot be won without strong support of the medical community. Therefore, conference organisers hope to, first of all, stimulate an all-European debate on medicalisation of tobacco control in the region, involving representatives of all medical associations, health care management systems, health insurance and pharmaceutical companies, governmental agencies as well as grass-roots physicians and nurses.

For further information, please contact: The Health Promotion Foundation, Sobieskiego 11 10/7. PL-00-764 Warsaw, Poland; tel: (+48 22) 64392 86; fax: (+48 22) 64450 24, ext. 2757; email: scientific@ectoh2002.org; website: www.ectoh2002.org 